\title{
Gas turbine gas path diagnostics: A review
}

\author{
Amare Desalegn Fentaye ${ }^{1, a}$, Syed Ihtsham Ul-Haq Gilani ${ }^{1}$ and Aklilu Tesfamichael Baheta ${ }^{1}$ \\ ${ }^{1}$ Department of Mechanical Engineering, Universiti Teknologi PETRONAS, 31750 Tronoh, Perak, Malaysia
}

\begin{abstract}
In this competitive business world one way to increase profitability of a power production unit is to reduce the operation and maintenance expenses. This is possible if the gas turbine availability and reliability is improved using the appropriate maintenance action at the right time. In that case, fault diagnostics is very critical and effective and advanced methods are essential. Gas turbine diagnostics has been studied for the past six decades and several methods are introduced. This paper aims to review and summarise the published literature on gas path diagnostics, giving more emphasis to the recent developments, and identify advantages and limitations of the methods so that beginners in diagnostics can easily be introduced. Towards this end, this paper, identifies various diagnostic methods and point out their pros and cons. Finally, the paper concludes the review along with some recommended future works.
\end{abstract}

\section{Introduction}

Gas turbine consists of complex, highly expensive, and precise elements operating at high pressure and temperature gas conditions. Failure or performance degradation of the engine strongly affects its operation. Performance of a gas turbine highly relies on the performance of gas path components, namely, compressor, combustion chamber, and turbine [1]. Component performance can be degraded attributable to the establishment of different fault cases, such as, fouling, erosion, blade tip clearance, corrosion, and object damages. The detailed description of these faults and their effects on the gas turbine performance including suitable maintenance advises can be found in the study led by Mejer-Homji et al. [2]. The occurrence of these faults result deviations of measurable engine parameters. To avoid these faults and maintain its best performance the gas turbine should have a mechanism that can detect, classify, and quantify developing engine faults as early as possible. This will help the operators to take action so that the engine is restored to the normal performance.

The change of the performance could be due to offdesign operation. That is to say because of load variation, ambient temperature or fuel delivery changes. Equivalently, the change of performance could be due to performance deterioration or malfunction. Hence, the operators should know the cause(s) of the change. In such cases the performance monitoring tool should be able to identify the cause(s). For instance, degradations are manifested by change of gas path measurable parameters or health indices. To predict the gas path parameters performance simulation model is required. Once the gas

\footnotetext{
a Corresponding author: dadorthot@gmail.com
}

path parameters are predicted, the non-measurable health indices would be computed for diagnostic purpose.

Diagnostics is the process of fault detection, isolation, and identification of a component or a system for an appropriate maintenance advice [3]. Specifically, gas turbine diagnostics can be for the sensor system, control system, fuel and oil system, vibration system, and gas path system [4]. Among them gas path diagnostics is the most critical tool and it works on the basis of engine performance deterioration [5].

Previously, large number of gas turbine diagnostics researches have been published focusing on component performance. As an example, Ogaji and Singh [6] developed advanced gas path fault diagnostic scheme for a single spool stationary gas turbines that can approximate both component faults and sensor faults, simultaneously. In the same way, Marinai [7] developed a diagnostic algorithm for gas path components of a gas turbine engine that can isolate single, dual and multiple component faults in the presence of noisy data. For more detail, an extensive review is available in [8]. However, recent researches [9-11] indicate that the existing algorithms still need an improvement and the area has some rooms for further study.

Thus, the aim of this paper is to present the literature survey on gas path diagnostics with a special focus on the current works and future trends. Section 2 point out the available advanced engine fault diagnostic approaches. In this part, the improvement of the methods as well as the recent research works utilizing them have also been presented. Then, section 3 provides the comparison among the approaches on the advantages and limitations. Lastly, section 4 belongs to the conclusion of the review, along with their implication for future works. 


\section{Gas turbine diagnostics methods}

In the field of gas turbine diagnostics several methods have been devised by the research community over the years [12-14]. Those methods can be classified into two main groups, namely model-based and data driven approaches [15]. Under these classifications a critical survey of the most commonly used methods and their applications are summarized here after.

\section{Model based diagnostics methods}

Model based diagnostics approaches rely on the thermodynamic model of a gas turbine. According to this approach the relationship among the gas turbine dependent parameters (e.g. pressure, temperature, fuel mass flow rate, and engine horse power) and the performance parameters (efficiency, pressure ratio and flow capacity) is determined through an explicit mathematical and thermodynamic equations [9].

In the field of model based diagnostics different approaches are available. Among these methods the gas path analysis (GPA) scheme is investigated very intensively by several authors, particularly, by those who worked on gas turbine gas path diagnostics [8]. Even though, gas turbine models for diagnosis are highly nonlinear, Urban [16] in 1967 introduced a simplified linear description, referred to as "linear gas path analysis" (LGPA), neglecting the measurement uncertainty and the non-linearity nature of the engine behavior. After that, the same author [17] and other authors [18, 19] proposed linear GPA algorithms with some modifications. Figure 1 illustrates the schematic representation of GPA methods.

According to the principle of linear GPA approach, the thermodynamic relationship among measurement parameters and performance parameters can be expressed as:

$$
\vec{Z}=H \bullet \vec{X}
$$

where $\vec{Z} \in R^{M}$ is engine measurable parameter vector and $\mathrm{M}$ is the number of measurable parameters, $\vec{X} \in R^{N}$ is engine components performance parameter vector and $\mathrm{N}$ is the number of component performance parameters, and $\mathbf{H}$ is Influence Coefficient Matrix (ICM).

In the same fashion, the engine measurable parameter changes and component performance changes can be related using Eq. (2).

$$
\Delta \vec{Z}=H \bullet \Delta \vec{X}
$$

The calculation of the performance parameter changes can be performed using the inverse of the linear ICM which is referred to as "Fault coefficient Matrix (FCM)" given by Eq. (3). when $M=N$.

$$
\Delta \vec{X}=H^{-1} \bullet \Delta \vec{Z}
$$

when $\mathrm{M}>\mathrm{N}$, Eq. (3) is over-determined and $\mathbf{H}^{-1}$ should be substituted by the pseudo-invers as defined in Eq. (4).

$$
\Delta \vec{X}=\left((H \bullet H)^{-1} \bullet H^{T}\right) \bullet \Delta \vec{Z}
$$

In fact, gas turbine performance deviation is not linear. To consider the non-linear behavior of the engine, an iterative Neuton Rapson method is applied to the linear GPA until the solution converges. For the first iteration, a small delta on the component performance is introduced and the ICM is generated followed by FCM. Then, using the FCM the performance parameter deviation vector is calculated. From the calculated results, a new ICM and FCM is generated and the procedure is repeated until the process converges. The convergence of the root mean square (RMS) value of the difference between the predicted performance value and the actual performance value can be checked using Eq. (5).

$$
R M S=\sqrt{\frac{\sum_{i=1}^{M}\left|Z_{i, p}-Z_{i, a}\right|^{2}}{M}} \leq \sigma
$$

where $Z_{i, p}$ is the predicted measurable parameter value, $Z_{\mathrm{i}, \mathrm{a}}$ is the actual measurement and $\sigma$ is a very small target RMS value.

The nonlinear gas path analysis (NLGPA) approach is introduced by Escher [20]. Since then several algorithms with some improvements have been contributed by others $[21,22]$. Marinai and Singh [5], have made a detailed review of NLGPA.

Recently, Li [23] developed a novel gas turbine performance and health state estimation method using adaptive GPA approach. According to this paper the proposed method can identify performance deteriorations accurately within a few seconds. The diagnosis effectiveness of three different GPA methods have been investigated using different test fault cases for double shaft gas turbine engine by Stamatis [24]. Similarly, the effectiveness of GPA methods in comparison with advanced artificial intelligence approaches have been examined and their pros and cons identified based on case studies for twin shaft gas turbine by Kong [25]. Also, Emil Larsson [26] developed a systematic design procedure to construct non-linear model based fault diagnosis method for industrial gas turbines. Jasmani [27], mentioned that effective measurement parameter selection is a very critical issue for GPA based engine diagnostics. To tackle this problem he introduced a new system by combining analytical approach and measurement subset concept. More recently, Chen et al. [28] proposed an approach that can select the optimal number of engine measurements for diagnostics. However, GPA techniques can diagnose gas turbine faults if and only if noise and bias doesn't exist and they cannot classify clearly the gas path component faults [25]. 


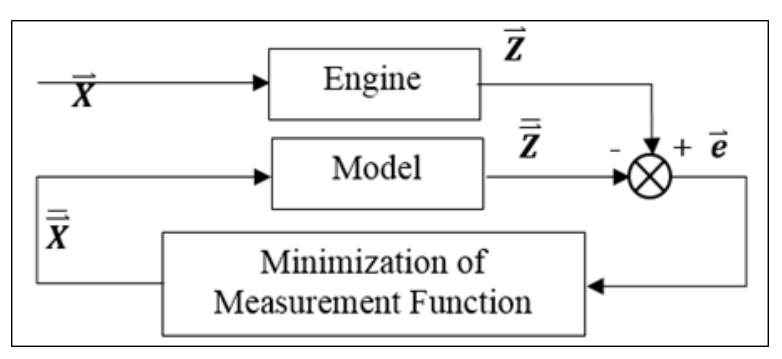

Figure 1. Schematic framwork of GPA method [8]

\section{Data driven diagnostics methods}

In this method, in order to develop the diagnostic tool, operational data with an appropriate quality, quantity, and type or performance data from model simulation, when operational data is not available, is required. In the field of gas turbine diagnostics data-driven methods are severely utilized by many researchers in the past several years. They can be categorized into two groups, namely, Artificial Intelligence (AI) and statistical methods [14]. According to Konar [29] AI can be defined as "the simulation of human intelligence on a machine, so as to make the machine efficient to identify and use the right piece of "Knowledge" at a given step of solving a problem". Alternatively, it can also be defined as " $a$ subject dealing with computational models that can think and act rationally" [30]. There are different AI methods used to develop diagnostics techniques. They are, Expert Systems, Genetic Algorithm (GA), Artificial Neural Networks (ANNs), Fuzzy Logic (FL) and their combinations. As far as statistical methods are concerned, engine faults are diagnosed by applying fundamental principles of statistics based on the available condition monitoring information (historical data). Even though, so far, both techniques have been extensively studied, but the most powerful and popular types of gas turbine diagnostic algorithms are from AI methods [9]. Thus, a comprehensive survey of this approach is presented hereafter.

\section{Artificial Neural Network (ANN) methods}

According to Simon [31], neural network can be defined as " a massively parallel distributed processor made up of simple processing units, which has a natural propensity for storing experimental knowledge and making it available for use". Usually the structure of neural network consists of an input layer with single or multiple neuron (s), one or more hidden layers with single or multiple neurons, and one output layer with single or multiple neurons. The numbers of input and output neurons are determined by the input and output parameters used. Furthermore, the optimal number of hidden neurons is determined based on a convergence criterion and the input-output mapping relationship characteristics. The neurons in the input, hidden and output layers are joined together using weighted connections. Then the network is trained to learn the relationship among the dependent and independent parameters by applying suitable error minimization technique [32]. Figure 2 illustrates the schematics of the topology of artificial neural networks. And the detailed description of different neural network techniques is available in [31].

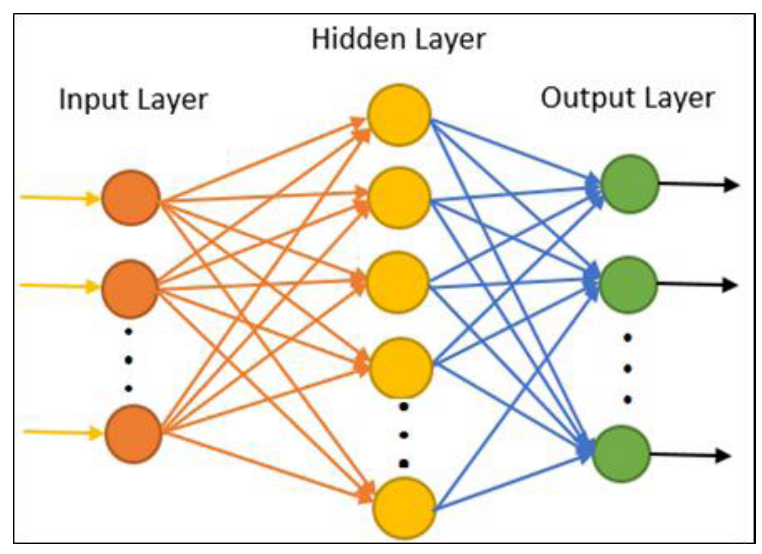

Figure 2. Architecture of a Feed Forward Back Propagation Neural Network

ANNs for gas turbine diagnosis is introduced by Denney et al. [33] in 1965. Since then a lot of ANN based diagnostic algorithms have been produced. For instance, Multilayer Perceptron Neural Network (MLPNN), Feed Forward Back Propagation (FFBP) Neural Network, Dynamic Neural Network [DNN], Auto-Associative Neural Network (AANN), Probabilistic Neural Network (PNN), and Nested Neural Network (NNN) are the most commonly used types [9, 31].

In the past decades, several studies have been done on engine diagnostics based on ANN techniques. For example, Ogaji [34] conducted a $\mathrm{PhD}$ research work on single, dual, and triple spool stationary gas turbines to develop a diagnostic algorithm that can diagnose both sensor and component faults simultaneously. The proposed mechanism can detect, isolate and identify single dual and triple sensor and component faults. Although, practically, more than three components can be faulty at the same time, in this research only three simultaneous component faults were considered. Ogaji and Singh [35] as well developed a sensor fault diagnostic system for a 2-shaft stationary gas-turbine engine using NNN. The network is capable to detect and isolate single and dual sensor faults even with the presence of noise and bias. However, the maximum combinations of sensors considered to be faulty at the same time were limited to two. Fast et al. [12], proposed a gas turbine fault diagnostic scheme using multi-layer FFBP-ANN. As per the report, artificial neural network is a suitable approach to develop a performance prediction model and fault diagnostic algorithm if an operational data is available in the required quality and quantity. The proposed tool can detect compressor fouling and is useful for an effective washing schedule. Similarly, Matuck [36] introduced MLPNN based engine diagnostics algorithm that can recognize a single, double and triple faults. Likewise, to evaluate component performance and sensor faults, hybrid diagnostic method was developed by Sampath [37] using GA and ANN techniques. It is shown that the accuracy, reliability and consistency of the results obtained from the hybrid technique is better than ANN and GA based algorithms. 
To answer the question why neural networks are more popular than the other AI methods, Patan et al. [38] conducted a research work on two different feed forward multilayer perceptron programs using DNN models taking into account the nonlinear behavior of the gas turbine and the robustness of a fault diagnosis scheme with respect to modelling uncertainty. It was pointed out that the fault diagnostic algorithms belonging to ANN were having smaller false alarms during detection, much more sensitive to early fault detection, high fault classification rate, and are efficient in fault identification than the other AI techniques.

Recently, Mohammadi et al. [39] modelled a fault detecting mechanism for dual-spool gas turbine engine using DNN technique based on model simulation data. The authors stated that, although, DNN is more known by its capability in nonlinear fault identification, in this research its identification capability was used for fault detection and it was effective. Sina et al. [40] also developed a new fault detection and isolation scheme using multiple layer perceptron dynamic neural network (MLPDNN) for a dual spool turbofan engine. It is presented that the proposed method can detect all ranges of fault cases (that is to say, low severity, medium severity, and high severity fault levels) with in an average time of 15.2 seconds. Similarly, to learn the nonlinear behavior of an engine, diagnostic mechanism for a dual spool aircraft jet engine has been modelled by Vanini et al. [9] using MLPDNN and multiple model approach. For each fault cases a corresponding network has been constructed in order to determine the occurrence time and location of the fault. It is shown that fault levels as low as $3 \%$ can be detected within 16 seconds. But the method has limitations on multiple fault isolation. Moreover, Vanini et al. [11] proposed an algorithm using AANNs to alleviate the limitations of both sensor and component fault detection and isolation tasks even with the existence of component and sensor faults concurrently. The detection and isolation performance of the new method has been checked for sensor faults, component faults, concurrent sensor and components faults, and concurrent component faults. And finally its performance has been validated using a known DNN based diagnostic algorithm. As per the results, the developed method is capable of sensor and component fault detection both one at a time and concurrently but it has a problem on concurrent fault isolation.

Generally, ANNs have many advantages, such as, they are effective in approximation for non linier models, can solve optimization problems, are cost effective for sensor diagnosis, have high prediction accuracy, have high computational speed after learning, and can perform well even with measurement biases, noisy data and missing data [34]. However, they have also some difficulties, for instance, their complexity increases for complex structures and it is difficult to understand how the training process is taking place, they have high computational time during training, and usually large amount of training data sets are required [12, 26, 40]. For more detail have a look at Table 1.

\section{Fuzzy Logic (FL) methods}

Fuzzy logic is one of the most commonly used AI methods to approximate the relationship between dependent and independent parameter vector values based on a set of if/then statements [34]. Fuzzy logic approach for diagnostics application consists of four basic components: fuzzy rules (sets of if-then statements), fuzzifier (the mechanism which maps numbers of input signals into the fuzzy set), inference engine (the technique used to determine the ways in which the fuzzy sets are combined with each other) and defuzzifier (the mechanism used to calculate the output values) [25]. The schematic representation of rule based fuzzy logic system shown in Figure 3. Thus, for the gas turbine diagnostics sets of measurement parameter deltas are given as input to the fuzzy logic algorithm in order to calculate the performance parameter deltas [7].

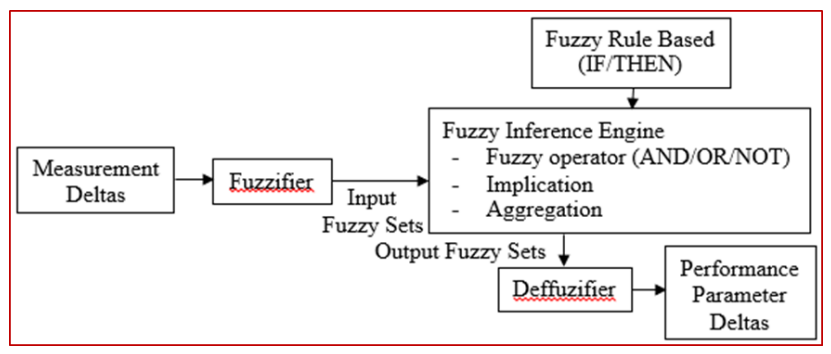

Fig. 3. Framework of a rule based fuzzy system.

After the earliest use of fuzzy logic by Fuster et al. [41] in 1997, several fuzzy logic based gas turbine gas path diagnostic techniques have been modelled by other researchers. Among these, Marinai [7] contributed a diagnostic model for a Rolls-Royce Trent 800 engine that can isolate both single and multiple component faults in the presence of measurement noise and sensor bias. The investigation of the method for multiple faults diagnosis was limited to dual component faults only. Similarly, Ganguli [42], developed engine measurements trend shift detection mechanism using median filters and fuzzy logic. Simulated data sets for clean and faulty engine cases were used to test the fault detection capability of the model and results showed that the detection based on filtered data was very accurate with negligible missed alarms and no false alarms. Guanguli [43], used fuzzy logic to develop a gas turbine engine gas path fault isolation algorithm with an accuracy of $95 \%$ and can work with poor quality data. Ogaji [44] also proposed a diagnostic algorithm for a modern military turbofan engine that can identify single component faults. Recently, Kyriazis et al. [45] proposed a fuzzy logic based gas turbine compressor fault diagnostic system using performance data. Its diagnostics effectiveness was compared with pattern recognition and PNN methods. It is mentioned that the developed method has good generality and effective in fault diagnostics like the other two methods.

However, the available fuzzy logic based diagnostic algorithms has limitations regarding multiple fault diagnostics and their effectiveness and performance needs more improvements [7]. 


\section{Genetic Algorithm (GA)}

GA is a method which mimics nature on the basis of Darwin's evolutionary theory of 'survival of the fittest' [46]. The GA is applied as an effective optimization tool to obtain a set of component parameters that produce a set of predicted dependant parameters, through a nonlinear gas turbine model that leads to predictions that best match the measurements [8]. The solution is obtained when an objective function, which is the measure of the difference between predicted values and measured values, achieves the minimum value.

The application of GA for gas turbine fault diagnosis was started in 1999 by Zedda [47] and have been investigated by several scholars for a couple of decades. It is mentioned that GA and ANN methods used as modelling technique to develop an integrated engine fault diagnostic tool for identifying shifts in component performance and sensor faults [36]. Recently, a comparative study was carried out by Kong et al. [48] on GPA and GA based diagnostic systems of a dual-spool turbofan engine. He stated that the diagnostic model based on GA is better than the model based on GPA particularly when sensor noise and bias are considered. In a similar manner, Kong [25] investigated the diagnostic effectiveness of GA in comparison with GPA and fuzzyneuro techniques based on case studies.

\section{Expert Systems (ES)}

An expert system is a computer program that used to capture human expert knowledge in the form of facts and rules to solve a problem or giving an advice $[5,8]$. The architecture of expert systems consist of four basic elements, user interface (used to acquire information and display results), inference engine (deals with all the reasoning operations of the system based on known facts and rules), knowledge base (contains facts and rules about the problem to offer the appropriate decision) and developer (stores information about current education) [25]. The configuration of an expert system is shown in Figure 4. Expert systems for engine diagnostics application can be classified as knowledge base and rule base. Several expert system based gas turbine diagnostic techniques are available in the open literature [8, 49]. However, these systems require precise inputs and rely entirely on knowledge of experts and extensive database of rules.

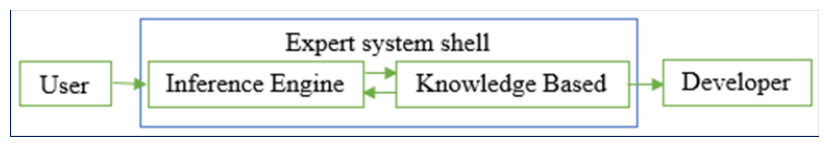

Fig. 4. Configuration of an expert system [25]

\section{Combined/hybrid Al methods}

In spite of the fact that, there is no single technique which addresses all the issues, it would be interesting to try and combine more than one technique to offset the limitations of one with the advantages of another. With regard to this, many combined AI techniques are proposed by different authors including fuzzy-neural networks (FNNs), neural-fuzzy systems, Genetic fuzzy logic, Genetics neural network [3, 33, 37]. Combined CI techniques are applied for diagnostics purpose and showed a better performance [37, 50, 51, 52, 53].

\section{Comparison of the methods: advantages and limitations}

In general, AI methods have many advantages than GPA methods. For example, they are capable to correlate input and output parameters efficiently even in the existence of limited data, they are efficient for complex systems with large amounts of equations and unknown variables, once they are developed, they have faster diagnosis time, and they can handle stochastic problems very efficiently. In addition, all AI based methods are capable to diagnose engine faults in the presence of noise and bias and are computationally more efficient. On the other hand, GPA based techniques have more advantages in terms of onboard implementation considerations than AI based methods. Also, they apply the real physics of the gas path and have low model complexity than AI based methods. Furthermore, during development, GPA based algorithms take less time than AI based systems.

As far as limitation is concerned, most of AI based techniques cannot give confidence limits on the output. In addition, pre-processing is required to limit the number of data inputs and unable to diagnose faults outside the range of data to which they have been exposed during the training time. Likewise, GPA based engine diagnostic methods have different problems including model uncertainties, model noise, model mismatch, need for more sensors, the existence of a very limited information in the public domain, and modelling difficulties at various operational conditions $[12,15,40]$.

To have clear view of the pros and cons of the aforementioned diagnostic methods, a comparison summary of major attributes of these methods is delineated in Table 1.

Table 1. Summary of advantages and limitations of the diagnostic methods

\begin{tabular}{|c|c|c|c|}
\hline Methods & \multicolumn{1}{|c|}{ Advantages } & \multicolumn{1}{c|}{ Disadvantages } \\
\hline & $\begin{array}{l}\text { complex, multi-dimensional, non-linear } \\
\text { systems can be modelled efficiently }\end{array}$ & $\begin{array}{l}\text { no standard (fixed optimal) data set for training } \\
\text { and testing } \\
\text { if there is operational data, system knowledge } \\
\text { is no more required } \\
\text { computer software is available for ANN }\end{array}$ & $\begin{array}{l}\text { longining time is required } \\
\text { selecting the most suitable model is to a great } \\
\text { extent trial and error and takes time }\end{array}$ \\
\hline
\end{tabular}




\begin{tabular}{|c|c|c|}
\hline & $\begin{array}{l}\text { modelling } \\
\text { diagnostics is possible with only a few } \\
\text { measurements (but with large data) [5] } \\
\text { can isolate multiple sensor and component } \\
\text { faults partially }[5,34,35] \\
\text { can isolate concurrent faults [11] } \\
\text { capable to solve complex gas path diagnostics } \\
\text { problems } \\
\text { able to deal with noise and bias } \\
\text { more preferable than others when a large } \\
\text { amount of noise is occurred } \\
\text { more preferable when an accurate diagnosis } \\
\text { result is required with a limited system } \\
\text { knowledge or lacking totally. }\end{array}$ & $\begin{array}{l}\text { since unable to perform outside the range of } \\
\text { data to which the network has been trained for, } \\
\text { a large amount of training and test data sets are } \\
\text { required. } \\
\text { Retraining is required to recognize, new data } \\
\text { sets, sensor noise level changes, and even } \\
\text { operating condition changes after engine } \\
\text { overhaul. } \\
\text { the process inside the network is a "black box" } \\
\text { A unique model is required to take care of only } \\
\text { a particular issue. }\end{array}$ \\
\hline FL & $\begin{array}{l}\text { few numbers of rules are required compared } \\
\text { to other rule based ESs } \\
\text { some fuzzy models can provide confidence } \\
\text { limits for their outputs } \\
\text { can manage diagnostics with only limited } \\
\text { numbers of measurements } \\
\text { relative to ANNs, they are much simpler to } \\
\text { translate and realize } \\
\text { can isolate single dual and triple sensor and } \\
\text { component faults concurrently [7] } \\
\text { can tackle high levels of measurement } \\
\text { uncertainties and sensor biases } \\
\text { able to deal with the non-linear nature of gas } \\
\text { turbine performance } \\
\text { can provide an approximate solution to a } \\
\text { diagnostics process } \\
\text { easy to set-up and fast computational } \\
\text { capability [7] }\end{array}$ & $\begin{array}{l}\text { Rules depend on the knowledge of subject } \\
\text { expert and diagnosis accuracy depends on the } \\
\text { available rules } \\
\text { large quantity of rules and training data sets are } \\
\text { required } \\
\text { they cannot recognize new data sets that the } \\
\text { model doesn't see in the training process } \\
\text { are inefficient in diagnostics with a very limited } \\
\text { number of data } \\
\text { does not admit model robustness } \\
\text { difficult to define exact queries that identify } \\
\text { specific faults }\end{array}$ \\
\hline GA & $\begin{array}{l}\text { able to deal with noise and bias } \\
\text { more preferable with other model based } \\
\text { methods }\end{array}$ & long \\
\hline ES & $\begin{array}{l}\text { simple to develop and easy to understand } \\
\text { preferable when the diagnostic problem is } \\
\text { well understood, stable, and human experts } \\
\text { are available to develop the knowledge base } \\
\text { (rules) } \\
\text { more suitable technique for stable and } \\
\text { predictable engine operating conditions, if } \\
\text { potential faults can be defined easily }\end{array}$ & $\begin{array}{l}\text { model accuracy highly depends on the up to } \\
\text { date knowledge of the human expert } \\
\text { significant number of comprehensive set of } \\
\text { rules are required } \\
\text { precise inputs required } \\
\text { give approximate results are not effective for } \\
\text { highly variable operating condition cases }\end{array}$ \\
\hline GPA & $\begin{array}{l}\text { more suitable for on-board application } \\
\text { the algorithm have direct relationship with the } \\
\text { gas turbine gas path physics } \\
\text { fairly high computational speed } \\
\text { capable to handle abrupt changes in } \\
\text { measurements due to operational damage } \\
\text { capable to multiple components fault isolation } \\
\text { [7] }\end{array}$ & $\begin{array}{l}\text { has a limitation on clear component fault } \\
\text { isolation [5] } \\
\text { for better prediction large number of sensors are } \\
\text { required } \\
\text { face a problem when } \mathrm{N}>\mathrm{M} \\
\text { can diagnose engine faults if and only if noise } \\
\text { and bias doesn't exist } \\
\text { modeling difficulties due to the existence of } \\
\text { limited information in the open domain } \\
\text { For large variations in component faults the } \\
\text { programme has convergence problem [34] }\end{array}$ \\
\hline
\end{tabular}

\section{Conclusions}

In the evolution of maintenance, fault diagnostics is a very critical advancement and works on the bases of condition. The existing gas turbine gas path diagnosis approaches have two major categories, namely, model based and data driven. In this paper, the research works using advanced diagnostic methods, GPA and AI, are reviewed. According to the review, the most powerful gas path diagnostic algorithms belongs to AI methods. Summary of pros and cons of these methods is given in Table 1. It is stated that the current AI based algorithms can successfully diagnose single component/sensor faults 
(SCF/SSF) both one at a time and simultaneously and multiple component/sensor faults (MCF/MSF) partially, even in the presence of noise and bias. However, the more recent works suggested that the following topics need future investigation.

1. Diagnostic tool that can address the entire gas turbine problems in an integrated manner

2. Method that can efficiently validate the performance and effectiveness of diagnostic algorithms.

3. Further improvement of gas path diagnostic methods concerning with complexity, computational efficiency, measurement uncertainties.

4. More efficient algorithm that can isolate concurrent faults and multiple faults.

5. Effective combined diagnostics and prognostics methods

6. Combining two or more AI methods and using for diagnostics (hybrid techniques)

\section{Acknowledgment}

This work was supported by a Yayasan University Technology PETRONAS (YUTP) project grant (Project Cost Centre No: 0153AA-A84).

\section{References}

[1] G. Vachtsevanos et al., Intelligent Fault Diagnosis and Prognosis for Engineering Systems, 1-434, (2007).

[2] C.B. Meher-Homji, A. Bromley, Gas Turbine Axial Compressor Fouling and Washing 33rd Turbomach. Symp., Texas A \& M University, (2004).

[3] Marco Mucino and Y. G. Li, A diagnostic system for gas turbines using GPA-Index, COMADEMC007-(2005).

[4] I. Loboda, Gas Turbine Condition Monitoring and Diagnostics, National Politechnique Institute, Mexico, (2010).

[5] L. Marinai, D. Probert, and R. Singh, Prospects for aero gas-turbine diagnostics: A review. Appl. Energy, 79(1): p. 109-126, (2004).

[6] S.O.T. Ogaji, R. Singh, Advanced engine diagnostics using artificial neural networks. Appl. Soft Comput., 3(3): p. 259-271, (2003).

[7] L. Marinai, Gas-path diagnostics and prognostics for aero-engines using fuzzy logic and Time series analysis" Cranfield University, $\mathrm{PhD}$ thesis, UK, (2004).

[8] Y.G. Li, Performance-analysis-based gas turbine diagnostics: A review. Proceedings of the Institution of Mechanical Engineers, Part A: Int. J. Power Energy Syst, 216(5): p. 363-377, (2002).

[9] Z.N.S. Vanini, K. Khorasani, N. Meskin, Fault detection and isolation of a dual spool gas turbine engine using dynamic neural networks and multiple model approach. Information Sciences, 259(0): p. 234-251, (2014).

[10] C. Romesis, Y.G. Li, Condition based maintenance (CBM) for gas turbines plants, Laboratory of Thermal Turbomachines National Technical
University of Athens, Greec \& Department of Power and Propulsion, Cranfield University, UK, (2013).

[11] Z.N.S. Vanini, N. Meskin, K. Khorasani, Multiplemodel sensor and components fault diagnosis in gas turbine engines using autoassociative neural networks. J. Eng. Gas Turbines Power, 136(9), (2014).

[12] m. Fast, M. Assadi, S. De, Development and multiutility of an ANN model for an industrial gas turbine. Appl. Energy, 86(1): p. 9-17, (2009).

[13] D. An, N.H. Kim, J.H. Choi, Practical options for selecting data-driven or physics-based prognostics algorithms with reviews. Reliability Engineering and System Safety, 133: p. 223-236, (2015).

[14] A.K.S Jardine, D. Lin, D. Banjevic, A review on machinery diagnostics and prognostics implementing condition-based maintenance. Mech. Syst. Sig. Process., 20(7): p. 1483-1510, (2006).

[15] R. Verma, N. Roy, R. Ganguli, Gas turbine diagnostics using a soft computing approach. Appl. Math. Comput., 172(2 SPEC. ISS.): p. 1342-1363, (2006).

[16] L.A. Urban, Gas Turbine Engine Parameter Interrelationships, HSD UTC, Windsor Locks, Ct., 1st edition, 1967, 2nd edition, (1969).

[17] L.A. Urban, Parameter Selection for Multiple Fault Diagnostics of Gas Turbine Engines. J Eng Power Trans ASME, 97 Ser A(2): p. 225-230, (1975).

[18] D.L. Doel, TEMPER - A Gas Path Analysis Tool for Commercial Jet Engines, J. Eng. Gas Turbines Power, Vol. 116, No. 1, pp.82-89, (1994).

[19] Volponi, The use of optimal estimation techniques in the analysis of gas turbines $\mathrm{PhD}$ thesis, Cranfield Univerrsity, UK, (1994).

[20] P. C. Escher, Pythia: An object-oriented Gas Path Analysis Computer Program for General Applications, $\mathrm{PhD}$ thesis, Cranfield University, UK, (1995).

[21] D.L. Doel, TEMPER - a gas-path analysis tool for commercial jet engines. J. Eng. Gas Turbines Power, 116(1): p. 82-89, (1994).

[22] A. Stamatis, K. Mathioudakis, K. Papailiou, Optimal measurement and health index selection for gas turbine performance status and fault diagnosis. J. Eng. Gas Turbines Power, 114(2): p. 209-216, (1992).

[23] Y.G. Li, Gas Turbine Performance and Health Status Estimation Using Adaptive Gas Path Analysis. J. Eng. Gas Turbines Power, 132(4): p. 041701-041701, (2010).

[24] A.G. Stamatis, Evaluation of gas path analysis methods for gas turbine diagnosis. J. Mech. Sci. Technol., 25(2): p. 469-477, (2011).

[25] C. Kong, Review on advanced health monitoring methods for aero gas turbines using model based methods and artificial intelligent methods. Int. J. Aeronaut. Space Sci., 15(2): p. 123-137, (2014).

[26] Emil Larsson, Model Based Diagnosis and Supervision of Industrial Gas Turbines, Linköping University, PhD thesis, Sweden, (2014). 
[27] M.S. Jasmani, Y.G. Li, Z. Ariffin, Measurement selections for multicomponent gas path diagnostics using analytical approach and measurement subset concept. J. Eng. Gas Turbines Power, 133(11), (2011).

[28] M. Chen, H. L. Quan, H. Tang, An Approach for Optimal Measurements Selection on Gas Turbine Engine Fault Diagnosis. ASME. J. Eng. Gas Turbines Power.;137(7): 071203-071203-9. doi:10.1115/1.4029171, (2015).

[29] B. Paul, A. Konar, A. K. Mandal, Fuzzy ADALINEs for gray image recognition, Neurocomputing, vol. 24, pp. 207-223, (1999).

[30] A. Konar, Artificial intelligence and soft computing : behavioral and cognitive modeling of the human brain, ISBN: 978-0-9778582-3-1, India, (2008).

[31] M. Kubat, Neural networks: a comprehensive foundation by Simon Haykin, Macmillan, 1994, ISBN 0-02-352781-7. The Knowledge Engineering Review, (2003).

[32] R. Ganguli, Gas Turbine Diagnostics Signal Processing and Fault Isolation, CRC Press (2013) Print ISBN: 978-1-4665-0272-7.

[33] G. Denney, F16 jet engine trending and diagnostics with neural networks. Proc. SPIE 1965, Applications of Artificial Neural Networks IV, 419 (September 2, 1993); doi:10.1117/12.152545.

[34] S.O.T. Ogaji, Advanced Gas-path Fault Diagnostics for Stationary Gas Turbines, Cranfield University, PhD thesis, UK, (2003).

[35] S.O.T. Ogaji, R. Singh, S.D. Probert, Multiplesensor fault-diagnoses for a 2-shaft stationary gasturbine. Applied Energy, 71(4): p. 321-339, (2002).

[36] G.R. Matuck, et al. Multiple faults detection of gas turbine by MLP neural network. in Proceedings of the ASME Turbo Expo, (2009).

[37] S. Sampath, R. Singh, An integrated fault diagnostics model using genetic algorithm and neural networks. J. Eng. Gas Turbines Power, 128(1): p. 49-56, (2006).

[38] K. Patan, M. Witczak, J. Korbicz, Towards robustness in neural network based fault diagnosis. Int. J. Appl. Math. Comput. Sci., 18(4): p. 443-454, (2008).

[39] R. Mohammadi, et al. Fault diagnosis of gas turbine engines by using dynamic neural networks. in Midwest Symposium on Circuits and Systems. (2011).

[40] T.B.S. Sina, Z.N.S. Vanini, K. Khorasani, Dynamic neural network-based fault diagnosis of gas turbine engines. Neurocomputing, 125(0): p. 153-165, (2014).

[41] P. Fuster, A. Ligeza, J. Aguilar Martin, adductive diagnostic procedure on an AND/OR/NOT graph for expert behaviour: Application to a gas turbine, 10th international congress and exhibition on condition monitoring and diagnostic

[42] R. Ganguli, Data rectification and detection of trend shifts in jet engine path measurements using median filters and fuzzy logic. J. Eng. Gas Turbines Power, 124(4): p. 809-816, (2002).
[43] R. Ganguli, Application of fuzzy logic for fault isolation of jet engines. J. Eng. Gas Turbines Power, 2003. 125(3): p. 617-623.

[44] S.O.T. Ogaji, et al., Gas-turbine fault diagnostics: a fuzzy-logic approach. Appl. Energy, 82(1): p. 8189, (2005).

[45] A. Kyriazis, et al. Gas turbines compressor fault identification by utilizing fuzzy logic-based diagnostic systems. in 9th European Conference on Turbomachinery: Fluid Dynamics and Thermodynamics, ETC 2011 - Conference Proceedings. (2011).

[46] Y.G. Li, An Genetic Algorithm Approach to Estimate Performance Status of Gas Turbine, ASME Paper No. ASME GT2008-50175, (2008).

[47] M. Zedda, Gas-turbine engine and sensor fault diagnosis, $\mathrm{PhD}$ Thesis, School of Mechanical Engineering, Cranfield University, UK, (1999).

[48] C.D. Kong, M.C. Kang, G.L. Park, Study on Condition Monitoring of 2-Spool Turbofan Engine using Non-Linear Gas Path Analysis Method and Genetic Algorithms, IJMMM, Vol. 1, No. 2, pp. 214-220, (2013).

[49] H. Abbasi Nozari, et al., Model-based robust fault detection and isolation of an industrial gas turbine prototype using soft computing techniques. Neurocomputing, 91(0): p. 29-47, (2012).

[50] Aiad Gannan, Cascade Testing and CFD Applied to Gas Turbine Performance Improvement with Compressor Cleaning, Cranfield University, PhD thesis, UK, (2012).

[51] A.L. Tamiru, Intelligent Fault Detection and Diagnosis System for A Cogeneration And Cooling Plant., Universiti Teknologi PETRONAS, PhD Thesis, Malaysia, (2012).

[52] B. Shahriari, A. N. Shahrbabaki, A. Shahriari, "Gas Turbine Fault Detection and Isolation Using Adaptive Neurofuzzy Inference System (ANFIS)", Advanced Materials Research, Vol. 1016, pp. 721725, Aug. (2014).

[53] R. Bettocchi, M. Pinelli, P. R. Spina, and M. Venturini, "Artificial Intelligence for the Diagnostics of Gas Turbines-Part II Neural-Fuzzy Approach ," J. Eng. Gas Turbines Power. Vol . 129, No. 3;,pp.720-729, (2007). 